\title{
PERFORMANCE OF NANO-HYDRAULIC TURBINE UTILIZING WATERFALLS
}

\author{
Toshihiko Ikeda ${ }^{\text {a }}$, Shouichiro Iio ${ }^{\text {b, }}$ and Kenji Tatsuno ${ }^{c}$ \\ ${ }^{a}$ Faculty of Engineering, Shinshu University, \\ 4-17-1 Wakasato, Nagano, 380-8553, Japan \\ Tel: +81 26269 5525; Fax: +81262695550 \\ E-mail address: ikeda21@shinshu-u.ac.jp \\ ${ }^{\mathrm{b}}$ Faculty of Engineering, Shinshu University, \\ 4-17-1 Wakasato, Nagano, 380-8553, Japan \\ E-mail address: shouiio@shinshu-u.ac.jp \\ ${ }^{c}$ Graduate Student, Faculty of Engineering, Shinshu University \\ 4-17-1 Wakasato, Nagano, 380-8553, Japan \\ E-mail address: t07a713@shinshu-u.ac.jp
}

\begin{abstract}
The aim of this investigation was to develop an environmentally friendly nano-hydraulic turbine utilizing waterfalls. A model of an impulse type hydraulic turbine constructed and tested with an indoor type waterfall to arrive at an optimum installation condition. Effects of an installation parameter, namely distance between the rotor and the waterfall on the power performance were studied. The flow field around the rotor was examined visually to clarify influences of installation conditions on the flow field. The flow visualization showed differences of flow pattern around the rotor by the change of flow rate and rotational speed of the rotor. From this study it was found that the power performances of the rotor were changed with the distance between the rotor and the waterfalls. The maximum power coefficient of this turbine is approximately $60 \%$. Also, to respond to changes in the waterfall flow rate, we placed a flat plate on the upper side of the rotor to control the water flow direction. As a result, we found that the coefficient of this turbine is increased with the flow rate and power could be obtained even when the flow rate changed by 3.5 times if the plate was placed on the upper side of the rotor. Although the power coefficient decreased when the plate was installed, the power coefficient still is from 53 to $58 \%$.
\end{abstract}

Key words: Nano-Hydraulic Turbine, Impulse turbine, Waterfalls, Performance, Field test.

\section{Introduction}


Clean energy has attracted attention under the current serious environmental conditions. In particular, expectations of renewable energies such as solar energy, wind power energy, hydro-energy, and biomass energy are quite high. Hydro-power has been used in Japan from old times as one of the largest domestic energy sources. In fact, about $10 \%$ of all supplying electric energy is provided by hydraulic power generation. On the other hand, it is said that in Japan, about half of the theoretical amount of potential water power, 100 million $\mathrm{kW}$ [1] is unharnessed. Although it is practically impossible to harness it all, we could expand the use of hydro-energy more than ever. Most unused hydro-power is geographically distributed over the country in small scale. Some have suggested that dam constructions can lead to the tremendous environmental damages. On the other hand, small/micro/nano hydropower has attracted much attention for recent years mainly because of decrease of construction place for large-scale plants and environmental conservation. There have been many researches about hydraulic turbines to utilize effectively as a small and territorially-distributed power systems, e. g. Savonius turbine [2, 3], pump reversed turbine [4], counter-rotating turbine [5], Darrieus turbine [6, 7, 8], gyro-type turbine [9, 10], positive displacement cross-flow turbine [11] and others. These turbines are applicable for mountain streams, small city stream, irrigation canals, water and sewage, and sand control dam. It is thought that this approach could lead to cheaper power generation without the environmental disruptions, compared with that produced by the large-scale and centralized hydroelectric plant. Compared to large-scale and centralized plant, small/micro/nano hydro-power generating facilities can be constructed at lower cost and have more candidate sites for construction, especially nano hydraulic turbine in this study generate electric power in consumping areas, and the generated power is used near the facilities for local production for local consumption. This type of generator can be used for, e.g. electric fences for the protection of crops from wild animals in mountainous farm land, microbial treatment toilets, emergency electric power sources at the time of disaster, or rural electrification to unelectrified areas in developing countries. For power generation using an extremely small hydro-power of less than several $\mathrm{kW}$, which is our target, it is important the installation, management and power generation cost. Therefore, we proposed the turbine for local production for local consumption by placing a turbine in the stream with almost no other accessory facilities e.g. training wall, penstock and control devices. In this study we conducted basic experiments using a model turbine to realize waterfall-type turbines that can be easily carried to, and installed on, the places where they are necessary, aiming at the utilization of small water energy. 
Our aim here is to develop hydraulic turbine for electricity generation utilizing waterfalls of extra-low head which is $2 \mathrm{~m}$ or less in small rivers and agricultural canals, etc. The rotor placed at the bottom of a waterfall will convert the kinetic energy of the falling water to electric energy. In this paper, we made an artificial indoor waterfall, conducted basic experiments such as measurement of power characteristics of the turbine and visualization of flow field, analyzed models, and investigated the influence of the relative position between the rotor and the waterfall to the rotor's performance, in order to make a guideline for installation conditions and designs for practical application. In order to achieve a stable generation even when a waterfall's flow rate changes, we also evaluated effect of a flat plate placed on the upper side of the rotor which controls the water flow direction.

\section{Nomenclature}

$C_{P} \quad:\left[=P / \rho g Q H_{F}\right]:$ power coefficient

$C_{P \max } \quad:$ maximum power coefficient

$D_{R} \quad:$ diameter of rotor $\quad[\mathrm{mm}]$

$g \quad$ : gravitational acceleration $\quad\left[\mathrm{m} / \mathrm{s}^{2}\right]$

$H_{F} \quad:$ head of waterfall $\quad$ [m]

$L_{B} \quad$ : chord of blade [mm]

$L_{F} \quad$ : distance between channel exit and blade $\quad[\mathrm{mm}]$

$L_{P} \quad$ : distance between channel exit and plate $\quad[\mathrm{mm}]$

$L_{R} \quad$ : length of rotor $\quad[\mathrm{mm}]$

$N \quad$ : rotational speed of rotor $\quad[\mathrm{rpm}]$

$P \quad:[=T \omega]:$ power output from rotor $\quad[\mathrm{W}]$

$Q \quad$ : flow rate of waterfall $\quad\left[\mathrm{m}^{3} / \mathrm{s}\right]$

$T \quad$ : torque experienced by rotor $\quad[\mathrm{Nm}]$

$U_{F} \quad:\left[=\sqrt{2 g H_{F}}\right]:$ impact velocity of waterfall with blade $\quad[\mathrm{m} / \mathrm{s}]$

$V_{t} \quad:\left[=\pi D_{R} N / 60 / 1000\right]:$ rotor tip speed $\quad[\mathrm{m} / \mathrm{s}]$

$\lambda \quad:\left[=V_{t} / U_{F}\right]:$ tip speed ratio

$\theta \quad$ : angle of blade [deg.]

$\rho \quad$ : water density $\quad\left[\mathrm{kg} / \mathrm{m}^{3}\right]$

$\omega \quad:[=2 \pi N / 60]:$ angular velocity of rotor $\quad[\mathrm{rad} / \mathrm{s}]$

\section{Experimental setup and procedure}


Figure 1 shows an overview of the experimental setup. The experiment was conducted with an artificial waterfall made in a laboratory. The water in the lower tank is pumped up to the upper open channel (see Fig. 2) and falls from the right-hand end of the channel. The rotor installed at the bottom of the waterfall receives the falling water, which rotates the rotor. The flow rate of the waterfall is controlled by a hand valve mounted downstream of the pump and is measured with an electromagnetic flow meter. Figure 2 shows the shape of the water channel, which is $250 \mathrm{~mm}$ wide and $1250 \mathrm{~mm}$ long. In order to prevent the water perturbation issuing from the water supply pipe, we placed a sponge under the outlet of the pipe and rectified the water flow by narrowing the width of the water channel and making its depth shallower toward the falling point. The rotor is illustrated in Fig. 3. It has a simple structure of 12 circular-arc shape blades sandwiched by 2 circular plates, and is made of transparent vinyl chloride. A stainless steel axis of $\varphi 15 \mathrm{~mm}$ penetrates the center of the end plates. The rotor diameter was $D_{R}=200 \mathrm{~mm}$ and the width was $L_{R}=250 \mathrm{~mm}$. The curvature radius of the blades was $23 \mathrm{~mm}$, the chord length $L_{B}=40 \mathrm{~mm}$, and the thickness $3 \mathrm{~mm}$. The rotor's rotation angle was set to $\theta=0^{\circ}$ in the horizontal position and $\theta>0$ in the rotation direction. Figure 4 shows the positional relation between the waterfall and the rotor. For the coordinates, we chose the center of the outlet of the water channel as the origin, the horizontal direction as the $x$ axis, the width direction as the $y$ axis, and the vertical direction as the $z$ axis. The head drop of the waterfall was defined as the $z$-direction distance from the origin to the upper end of the blade at $\theta=-30^{\circ}$. The relative position of the waterfall and the rotor was adjusted by shifting the water channel in the $x$ direction. For practical application, we need to respond to changes in the flow rate of a waterfall and so we installed a plate on the upper side of the rotor in our study. With this method, we do not have to change the relative position of the waterfall and the rotor, even when the flow rate of the waterfall changes. We used a transparent acrylic plate with a width of $250 \mathrm{~mm}$, the same as that of the rotor, so that we could observe the waterfall.

The power output characteristics were evaluated by measurement of the rotation number and torque of the rotor axis. A powder brake (Mitsubishi Electric, ZKG-YN20) was used for loading, and the brake and torque meter (Ono Sokki, SS-010) were connected to the rotation axis via a coupling. The measurement started from the unloaded state and torque $T$ and rotation number $N$ were measured to calculate output $P$ as the load was increased by the powder brake.

The experimental conditions are given in Table 1. Taking account of daily observable change in the flow rate of actual waterfalls due to climate or seasonal change, we set the minimum flow rate to 
$Q=1.0 \times 10^{-3} \mathrm{~m}^{3} / \mathrm{s}$ and the maximum flow rate to $Q=3.5 \times 10^{-3} \mathrm{~m}^{3} / \mathrm{s}$. We also took into consideration the falling position of the waterfall that could change with changes in the flow rate, and adjusted the horizontal distance between the waterfall and the rotor according to the flow rate. As will be discussed in detail in 4.1 , we set the head drop to $H_{F}=570 \mathrm{~mm}$, considering the distance from the falling point to the collapsing point of the waterfall.

\section{Experimental Results and discussion}

\subsection{Flow pattern of waterfall}

The waterfall is presented in Fig. 5. It was shot from the $x$ and $y$ directions and to measure longitudinal coverage at $z=0-1000 \mathrm{~mm}$. In Fig. 5, visualized images of the waterfall at (a) $Q=1.0 \times 10^{-3}$ $\mathrm{m}^{3} / \mathrm{s}$ and (b) $Q=3.5 \times 10^{-3} \mathrm{~m}^{3} / \mathrm{s}$ are shown. At $Q=1.0 \times 10^{-3} \mathrm{~m}^{3} / \mathrm{s}$, the waterfall became narrower downstream and collapsed at around $z=1000 \mathrm{~mm}$. At $Q=3.5 \times 10^{-3} \mathrm{~m}^{3} / \mathrm{s}$, it also became narrower downstream but did not collapse as far as we could see in the shot image. The collapsing point of the waterfall moved downward as the flow rate increased. The thickness of the waterfall was about 5 $\mathrm{mm}$. Since the water energy is proportional to the head drop, we would like to place the rotor in as low a position as possible. However, the rotor should be placed on the upstream side of the collapsing point of the waterfall, and we hence determined the position of the rotor in such a way that the waterfall would hit the blades at $z=570 \mathrm{~mm}$ when $Q=1.0 \times 10^{-3} \mathrm{~m}^{3} / \mathrm{s}$. Figure 6 shows longitudinal coverage of the waterfall at $Q=1.0,2.0$, and $3.5 \times 10^{-3} \mathrm{~m}^{3} / \mathrm{s}$. With the increase in the flow rate, the longitudinal coverage point moved from the origin. When the flow rate increased from $Q=1.0 \times 10^{-3} \mathrm{~m}^{3} / \mathrm{s}$ to $Q=3.5 \times 10^{-3} \mathrm{~m}^{3} / \mathrm{s}$, the longitudinal coverage increased 1.6 times at $z=500 \mathrm{~mm}$ and 1.8 times at $z=1000 \mathrm{~mm}$.

\subsection{Power performance of rotor}

We conducted the experiment under the conditions in Table 1 to study how the flow rate and the horizontal distance between the waterfall and the rotor blades affected the power output characteristics. The measured power output characteristics are shown in Fig. 7, where (a) and (b) represent the data at the minimum and maximum flow rates, respectively. In Fig. 7(a), the data points of $C_{P}$ are distributed in a parabolic shape and have the maximum value $C_{P \max }$ for any $L_{F} / D_{R}$. The value of $\lambda$ at which $C_{P}$ reaches the maximum lies in the range of $0.5-0.7$. When $\lambda$ is out of range, $C_{P}$ is small. The value of $\lambda$ that gives $C_{P \max }$ is smaller with larger $L_{F} / D_{R}$. $C_{P \max }$ is the largest, 0.58 , at 
$L_{F} / D_{R}=0.85$. When $L_{F} / D_{R}$ changes from its optimal value of 0.85 to 0.80 by about $6 \%, C_{P \max }$ decreases by about $10 \%$. In Fig. 7(b), the behavior of $C_{P-\lambda}$ resembles that in Fig. 7(a) for any $L_{F} / D_{R}$ ratio, and when the ratio changes from the optimal value of 1.33 to 1.28 by about $4 \%, C_{P \max }$ decreases by as much as about $20 \%$. The value of $C_{P \max }$ was larger at a larger flow rate and became $C_{P \max }=0.66$ in (b). As shown in Fig. 6, the change in longitudinal coverage due to the change of $Q$ was large, and it is hence quite important to respond to changes in flow rate for the waterfall wheel.

Next, we visualized the flow field around the rotor to clarify the cause of changes in power output characteristics due to the change of $Q$ or $\lambda$. Figure 8 shows the photographs of the waterfall that realized the largest $C_{P \max }$ at each of the 2 flow rates in Fig. 7. For $Q=3.5 \times 10^{-3} \mathrm{~m}^{3} / \mathrm{s}$, photographs with lower and higher $\lambda$ are also presented. We used a digital CCD camera (Nikon D70) for photograph shooting and a strobe light (SUNPAK B3000S) for the light source. The images were shot from the direction of the rotor axis. We made the light sheet shaped through a 2-mm-wide slit. The lighting position was set at the central cross section of the rotor width. We obtained still images by setting the light-emitting time to $1 / 1200 \mathrm{sec}$. and the camera's shutter speed to 1/6400 sec. In Fig. 8 (a), the water falling from the upper left-hand side hit the left-hand end of the blade at $\theta=-30^{\circ}$. The waterfall came onto the center of the blade at $\theta=0^{\circ}$ and the right-hand side of the blade at $\theta=30^{\circ}$. After hitting the blade, the water flowed along the blade surface and separated to the inside and outside of the rotor. Under these experimental conditions, the water volume flowing to the outside of the rotor was larger than that to the inside. Also, the water that flowed into the rotor flowed out along the back surface of the blade, and on the right-hand half of the rotor, the water became droplets flying apart. In Fig. 8 (b), (c) and (d) $\left[Q=3.5 \times 10^{-3} \mathrm{~m}^{3} / \mathrm{s}\right]$, the waterfall hit the left-hand end of the blade at $\theta=-30^{\circ}$, the right-hand side of the center of the blade at $\theta=0^{\circ}$, and the right-hand end of the blade at $\theta=30^{\circ}$. Compared to the small flow rate case, the hitting point shifted toward the right-hand side of the blade (toward the center of the rotor), which was because the increase in the flow rate increased inflow angle $\alpha_{1}$ of the waterfall. After collision against the blade, the waterfall flowed along the blade and separated into the outside and inside of the rotor. The water flow inside the rotor had a clear dependence on $\lambda$. As shown in Fig. 8(b), the inside of the rotor was filled with the water, which flowed out from the blade's back surface as the rotor rotated. This water interfered with the rotation of the rotor and decreased $C_{P}$. This is why the power coefficient was small in Fig. 7(b). In Fig. 7, we did not obtain $C_{P}$ for smaller values of $\lambda$ because the influent water caused considerable reduction of the rotational speed of the rotor and reduced the rotor's power. In these experimental conditions, the 
rotor often stopped during power measurement. Figure 8(c) shows the water flow in cases where we could obtain the maximum power coefficient. The water flowing into the rotor flowed out from the rotor along the blade's back surface as the rotor rotated. The volume of the water flowing to the inside of the rotor was larger than that in Fig. 8(a). In all cases, the water inside the rotor reduces the efficiency more or less, and we need to examine the blade angle and other factors in future. In Fig. 8(d) where $\lambda$ was large, the fall velocity of the waterfall and the circumferential velocity of the blades were equal and the waterfall flowed downward almost without interfering with the blade. Accordingly, the energy of the waterfall did not transfer to the rotor and the rotor could not output power.

Figure 9 shows the relation between the flow rate and the maximum power coefficient of the rotor. The positional relation of the waterfall and the rotor at each flow rate was set by optimal distance $L_{F O}$. The data indicated by square in the figure will be explained in the next paragraph. If we take a look at the experimental data indicated by circle, we see that $C_{P \max }$ increases with $Q$ as far as $1.0 \times 10^{-3}<Q<2.0 \times 10^{-3} \mathrm{~m}^{3} / \mathrm{s}$. For $Q>2.0 \times 10^{-3} \mathrm{~m}^{3} / \mathrm{s}, C_{P \max }$ remained almost the same irrespective of $Q$. As a result, $C_{P \max }$ took the minimum value of $C_{P \max }=0.58\left[Q=1.0 \times 10^{-3} \mathrm{~m}^{3} / \mathrm{s}\right]$ and the maximum value of $C_{P \max }=0.66\left[Q=3.5 \times 10^{-3} \mathrm{~m}^{3} / \mathrm{s}\right]$. We found that a difference of about $12 \%$ could arise in the maximum power even when the positional relation between the waterfall and the rotor was optimal.

We theoretically analyzed the cause of the change of $C_{P \max }$ with the change of $Q$, using the model in Fig. 10. The figure shows a quarter part of the rotor and the blade at $\theta=-30^{\circ}$. We conducted analysis with a single blade of the rotor. The water came from the upper left-hand side into the rotor at flow rate $Q_{1}$ and hit the blade at velocity $V_{1}$. After colliding with the blade, the water separated along the blade surface into 2 flows, which had flow rates $Q_{2}$ and $Q_{3}$, respectively. The ratio of flow rate $Q_{2}$ and $Q_{3}$ was determined from the waterfall's angle hitting the blade and the angle between the waterfall and the tangent line to the blade. We assumed that the outflow speed was equal to inflow speed $V_{1}$, ignoring fluid friction against the blade surface. The circumferential velocity of the rotor, $U_{1}, U_{2}$, and $U_{3}$, were determined from the radius at each point and the rotor's rotational speed with power coefficient $C_{P \max }$, which was obtained in the power output characteristic measurement. The position at which the waterfall hit the blade and its inflow angle $\alpha_{1}$ were determined from visualized images shown in Fig. 8(a) and (c). We also calculated $P_{\max }$ from the momentum change in the waterfall flowing to/from the blade, using the momentum theory. Since we could observe the waterfall's collision with the blade in the angle range of $\theta=-30 \sim 30^{\circ}$, we divided the range into $5^{\circ}$ 
sections to calculate $P_{\max }$ at each angle section. From the average value of $P_{\max }$ in this angle range, we finally obtained $C_{P \max }$.

Figure 9 shows the result of the calculation. The theoretical value was $C_{P \max }=0.77 \sim 0.83 . C_{P \max }$ was lowest at $Q=1.0 \times 10^{-3} \mathrm{~m}^{3} / \mathrm{s}$ and was almost constant when $Q>2.0 \times 10^{-3} \mathrm{~m}^{3} / \mathrm{s}$. This tendency qualitatively coincides with the experiment. The minimum value was $C_{P \max }=0.77\left[Q=1.0 \times 10^{-3} \mathrm{~m}^{3} / \mathrm{s}\right]$ and the maximum was $C_{P \max }=0.83\left[Q=3.5 \times 10^{-3} \mathrm{~m}^{3} / \mathrm{s}\right]$, the difference between which was $7.8 \%$. The analytic value was larger than the experimental value because the fluid friction of the water flow along the blades was ignored in the analysis and the influence of the water coming inside the rotor was not reflected. When flow rate $Q$ changed, the position at which the waterfall hit the blade did not change but the inflow angle of the waterfall changed, as checked in the visualized images. It was hence clarified that the change of $C_{P \max }$ with the change in flow rate was caused by the change in the inflow angle of the waterfall.

\subsection{Response to flow rate change with a flat plate}

For practical application of the waterfall hydraulic turbine, changes in flow rate become a problem. As the flow rate of a waterfall changes from season to season and from time to time, the optimal position of the rotor $\left(L_{F O}\right)$ also changes as discussed above. However, it is not practical to move the optimal position of the rotor in accordance with the flow rate change because of the complicated mechanism. We therefore need to respond to the flow rate change of a waterfall while keeping the rotor in a specific position. So we considered the use of a plate as shown in Fig. 4. Although we could use other shaped boards, we selected a flat plate of the simplest shape as the first step. In this section, we describe the result of our study on the relation between the flow rate and the power output characteristics when the plate is used. The rotor was fixed at the position in the horizontal distance of $L_{F}$ from the waterfall that gave the maximum power output efficiency at the smallest flow rate of $Q=1.0 \times 10^{-3} \mathrm{~m}^{3} / \mathrm{s}$. The position of plate $L_{P}$ was determined in such a way that the waterfall flowed along the plate and into the optimal collision point on the blade. The plate was mounted vertically.

Figure 11 shows the power output characteristics. At any flow rate, the data points of $C_{P}$ are distributed in a parabolic shape and we can see no significant difference in the shapes other than their maximum values. We do not have data for $\lambda<0.4$ because the load increased at around $\lambda=0.4$ and smaller. Namely, the rotational speed decreased, the water stayed inside the rotor, and the rotor 
stopped. So we could not measure the power output characteristics in this parameter range.

At any flow rate, we had $C_{P \max }$ when $\lambda=0.5$. We consider that this is because the water collision point on the blade did not change much when we used the plate. Without the plate, the value of $\lambda$ at which the rotor had $C_{P \max }$ varied as $L_{F}$ changed, as in Fig. 7 (a) and (b). $C_{P \max }$ reached the highest value of 0.58 at $Q=1.0 \times 10^{-3} \mathrm{~m}^{3} / \mathrm{s}$, in which the waterfall collided against the blade without contacting the plate. The plate thus had the effect of adjusting the waterfall's flowing-in position on the blade to the most appropriate point by receiving increased water when the flow rate increased. The waterfall always hit the plate under any condition as far as $Q>1.0 \times 10^{-3} \mathrm{~m}^{3} / \mathrm{s}$. In this case, $C_{P \max }$ took the largest value at $Q=1.5 \times 10^{-3} \mathrm{~m}^{3} / \mathrm{s}$. We could easily imagine that the waterfall's collision against the plate would reduce the efficiency. At $Q=3.5 \times 10^{-3} \mathrm{~m}^{3} / \mathrm{s}$, we had the lowest $C_{P \max }$, i.e., $C_{P \max }=0.53$, which was smaller by $20 \%$ than that measured without the plate. The flow field in this case is presented in Fig. 12. In Fig. 12 (a), the waterfall came to the rotor without hitting the plate at $Q=1.0 \times 10^{-3} \mathrm{~m}^{3} / \mathrm{s}$, and in (b), the waterfall hit the lower side of the center of the plate, flowed along the plate, and fell vertically down to the rotor at $Q=2.0 \times 10^{-3} \mathrm{~m}^{3} / \mathrm{s}$. In Fig. 12 (c) at $Q=3.5 \times 10^{-3} \mathrm{~m}^{3} / \mathrm{s}$ larger than that in (a) and (b), the waterfall hit the plate at the upper side of the plate center. After hitting the plate, the water fell down vertically as in (b), flowed into the rotor, and collided against the blade. Although we cannot clearly recognize it in Fig. 12, we could observe that the thickness of the waterfall after collision against the plate was almost constant, independent of $Q$, and broadening of the waterfall in the width direction of the plate changed with $Q$. So the width of the plate should be determined based on broadening of the waterfall at the maximum flow rate, and the width of the rotor should be determined in accordance with it. Also, since there was almost no change found in the water layer thickness after collision against the plate even when the flow rate of the waterfall changed, the blade's chord length of $40 \mathrm{~mm}$ would be suitable for responding to the flow rate range. Figure 13 shows $C_{P \max }$, derived for each $Q$ in Fig. 11. In the figure, the data of $C_{P \max }$ obtained with no plate used are also plotted. When the plate was mounted, $C_{P \max }$ decreased and the tendency became more significant at larger $Q$. With the plate installed, the reduction of $C_{P \max }$ at larger $Q$ could be caused by velocity energy loss when the waterfall collided against the plate or by energy loss due to fluid friction when the waterfall flowed along the plate. Namely, when $Q$ was large, the collision angle of the waterfall and the plate was large and their contact length was long. This resulted in large loss. In the presence of the plate, $C_{P \max }$ was reduced but reached constant when $Q$ became relatively large. We thus found that stable power generation could be obtained despite a large change of $Q$ just 
by introducing a simple piece of plate without shifting the rotor. This is an extremely useful result for practical application.

\section{Field test}

The photograph and schematic image of the nano-hydroelectric unit with the waterfall type turbine set in a small flume is shown in Fig. 14. The demonstration unit was placed in the rural area at Suzaka city in Nagano prefecture in Japan. This area is mountain-ringed region and has rich-water for agricultural use. The solar cell could not produce sufficient power because of few hours of sunlight. This turbine is suitable for such a place for local production for local consumption. The unit has been operated for using power supply to electrified fences which prevent crop damage from animals. The unit has been operated smoothly without any major disruptions since the demonstration started in April, 2007. It costs 1.9 million yen to this unit because it is custom made. The rotor diameter was decided to become similar shape of the laboratory type rotor in consideration of the head of waterfall. The head of the waterfall is $1.2 \mathrm{~m}$, the rotor diameter is $400 \mathrm{~mm}$. The rotor length is $500 \mathrm{~mm}$, it is the same as the waterfall width at the flume exit. The rotor was constructed from galvanized steel mounted on a $40 \mathrm{~mm}$ diameter stainless steel rod. One end of the rotor shaft is coupled to a sprocket wheel and to upper mounted generator by a roller chain. The small headframe is bolted to the top of the channel wall, and enable lifting of the turbine and generator equipment. The weight of the unit is approximately $120 \mathrm{~kg}$. The unit allows users very easy and quick set and release by themselves, and can supply average power of 100-200 watts. Its total efficiency is approximately $20 \%$ including of power coefficient of the rotor, efficiency of generator and mechanical losses. The unit provides sufficient generation to meet the demand, but the power coefficient of the rotor is lower than that of the laboratory type. It is partly because of the mechanical losses, but mainly because of the too much disturbance of the waterfall. It is evident from comparison of Fig. 5 with Fig. 14. This result shows that the power coefficient of the rotor is strongly affected by the natural condition of waterfall. This will be the subjects of further study.

\section{Conclusions}

This study has explored the basic performance of the hydraulic turbine utilizing waterfall. Measurement of power characteristics of the turbine and visualization of flow field, model analysis were conducted and it was clarified the influence of the relative position between a rotor and 
waterfall on the rotor's performance. In addition, in order to achieve a stable generation even when a waterfall's flow rate changes, we also evaluated effect of a flat plate placed on the upper side of the rotor which controls the water flow direction. The following conclusions can be drawn:

1) In the measurement of power output characteristics of a waterfall type rotor without a plate, the maximum power coefficient $C_{P \max }=0.58 \sim 0.66$ if the rotor is placed on an optimum position for the flow rate of the waterfall.

2) From the study of the relation between the waterfall flow rate and the rotor power coefficient, we found that the coefficient increased with the flow rate. Theoretical analysis of the cause based on the momentum theory showed that a change of angle at collision of the water against the blades led to a change of the rotor power coefficient. We did not take account of the water flow into the rotor or fluid friction in our analysis. However, the result coincides qualitatively with the experimental data and should be used to make a useful guideline for examination of blade shape.

3) The effect of the plate placed on the upper side of the rotor was confirmed. The power could be obtained even when the flow rate changed by 3.5 times. Namely, we do not have to move the rotor to another position when the flow rate of the waterfall changes. This is an extreme advantage from a practical application viewpoint. Although the rotor power coefficient decreased when the plate was installed, we still had $C_{P \max }=0.53 \sim 0.58$.

4) From the result of the field test, we found that the power coefficient of the rotor reduced to one-third of that of the laboratory type. This result shows that the power coefficient of the rotor is strongly affected by the natural condition of waterfall.

We continue our study on the rotor diameter, blade shape, and number of blades for optimum performance, with taking into consideration the characteristics of natural waterfall.

\section{Acknowledgements}

This work was supported partly by the Grant-in-Aid for Exploratory Research under Grant No.19651033 from Japan Society for the Promotion of Science.

\section{References}

[1] Federation of Electric Power Companies of Japan, publicity matter 2003-2004, CD-ROM.

[2] Nakajima M, Iio S, Ikeda T. Performance of double-step Savonius rotor for environmentally friendly hydraulic turbine. J Fluid Sci and Tech 2008; 3(3), 410-10.

[3] Nakajima M, Iio S, Ikeda T. Performance of Savonius rotor for environmentally friendly hydraulic 
turbine. J Fluid Sci and Tech 2008; 3(3), 420-10.

[4] S Derakhshan, A Nourbakhsh. Experimental study of characteristic curves of centrifugal pumps working as turbines in different specific speeds. Experimental Thermal and Fluid Science 2008; 32, 800-8.

[5] Kanemoto T, Furukawa A, Ikeda T, Iio S. Research and development on hydroelectric units for micro-hydro power utilization. Proceedings of the 2007 Small Hydropower/Ocean Energy International Co-Seminar and Sixth Hydropower Technical Association Seminar 2007; 3-7.

[6] Takamatsu Y, Furukawa A, Okuma K, Takenouchi K. Experimental studies on a preferable blade profile for high efficiency and the blade characteristics of Darrieus-type cross-flow water turbine. JSME Int. J., Ser. II 1991; 34(2), 149-8.

[7] Furukawa A, Okuma K. Extra-low head hydropower utilization with Darrieus-type Runner. Turbomachinery $1995 ; 30(3), 142-6$.

[8] Matsuura K, Okuma K, Watanabe S, Furukawa A. Operation characteristics of ducted Darrieus turbine for extra-low head hydropower. Proceedings of Renewable Energy 2006; CD-ROM O-N-4-5, 2732-4.

[9] Kanemoto T, Misumi H, Inagaki A, Muraoka R. Development of new type hydraulic turbine suitable for shallow stream. JSME annual meeting 2002; 2002(3), 173-2.

[10] Inagaki A, Kanemoto T. Gyro-type hydraulic turbine suitable for shallow stream (2nd Report). Trans. JSME, ser. B 2005; 71(704), 1092-7.

[11] Phommachamh D, Kurokawa J, Choi Y D, Nakajima N, Motohashi T. Development and performance of a micro positive displacement hydropower turbine. Turbomachinery 2006; 34(10), 621-11.

\section{Figure Captions}

Fig. 1 Experimental setup

Fig. 2 Open channel

Fig. 3 Rotor and blade specifications

Fig. 4 Test section and installation condition of plate

Fig. 5 Flow patterns of waterfall (a) $Q=1.0 \times 10^{-3}\left[\mathrm{~m}^{3} / \mathrm{s}\right]$, (b) $Q=3.5 \times 10^{-3}\left[\mathrm{~m}^{3} / \mathrm{s}\right]$

Fig. 6 Trajectory pattern of waterfall

Fig. 7 Power performance of rotor without plate (a) $Q=1.0 \times 10^{-3}\left[\mathrm{~m}^{3} / \mathrm{s}\right]$, (b) $Q=3.5 \times 10^{-3}\left[\mathrm{~m}^{3} / \mathrm{s}\right]$

Fig. 8 Flow patterns in rotor without plate (a) $Q=1.0 \times 10^{-3}\left[\mathrm{~m}^{3} / \mathrm{s}\right], \lambda=0.46, C_{P}=0.58$, (b) $Q=3.5 \times 10^{-3}\left[\mathrm{~m}^{3} / \mathrm{s}\right]$, $\lambda=0.34, \quad C_{P}=0.40,(\mathrm{c}) Q=3.5 \times 10^{-3}\left[\mathrm{~m}^{3} / \mathrm{s}\right], \quad \lambda=0.56, \quad C_{P \max }=0.66,(\mathrm{~d}) Q=3.5 \times 10^{-3}\left[\mathrm{~m}^{3} / \mathrm{s}\right], \quad \lambda=1.00, \quad C_{P}=0.06$

Fig. 9 Maximum power characteristics without plate 
Fig. 10 Model for analysis

Fig. 11 Power output characteristics with plate

Fig. 12 Visualization images with plate (a) $Q=1.0 \times 10^{-3}\left[\mathrm{~m}^{3} / \mathrm{s}\right]$, (b) $Q=2.0 \times 10^{-3}\left[\mathrm{~m}^{3} / \mathrm{s}\right]$, (c) $Q=3.5 \times 10^{-3}\left[\mathrm{~m}^{3} / \mathrm{s}\right]$

Fig. 13 Maximum power output characteristics

Fig. 14 Nano-hydroelectric unit with waterfall type turbine set in a small flume of Suzaka city in Japan

Table Caption

Table 1 Experimental conditions 


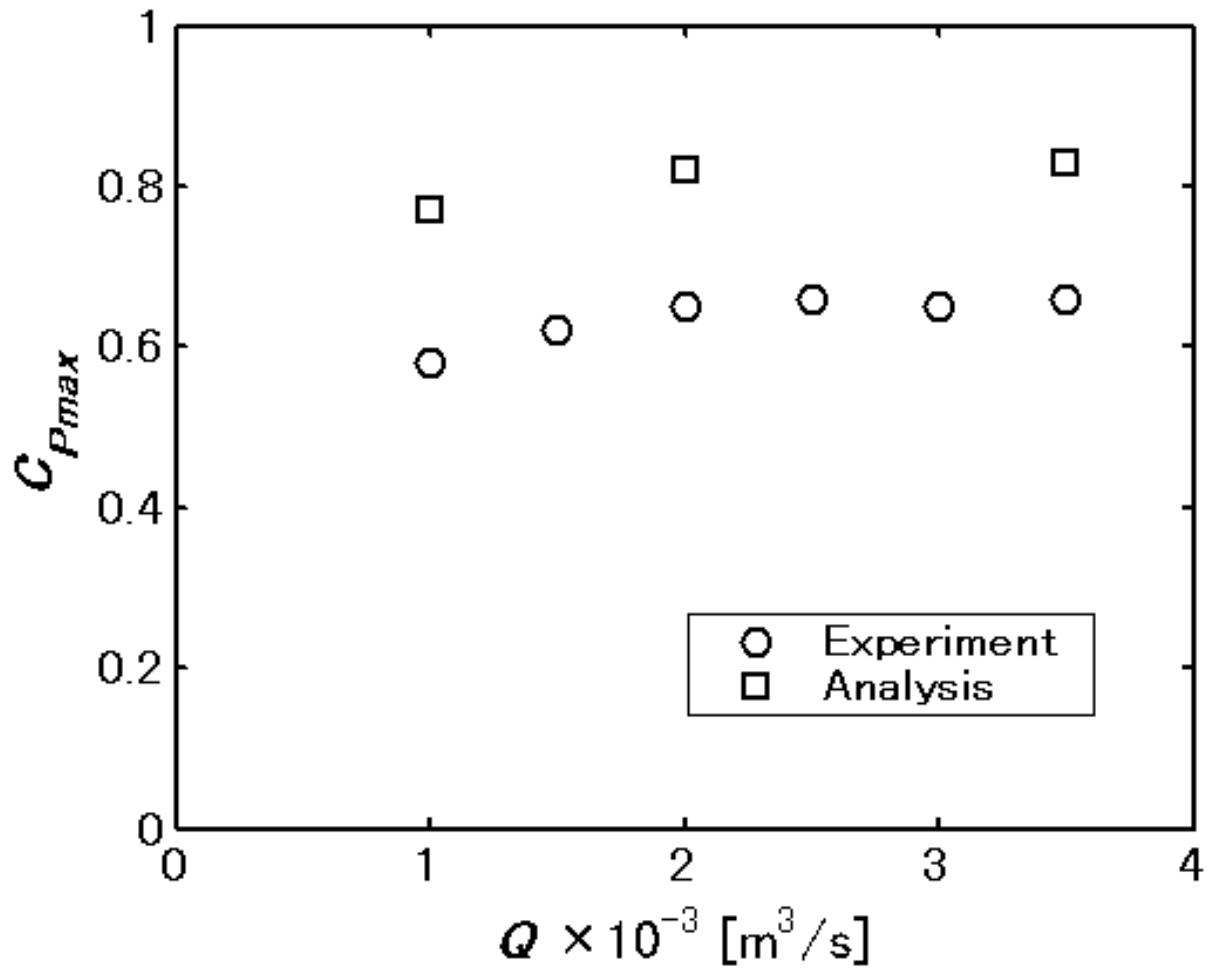

Fig. 9 (Revised version) 


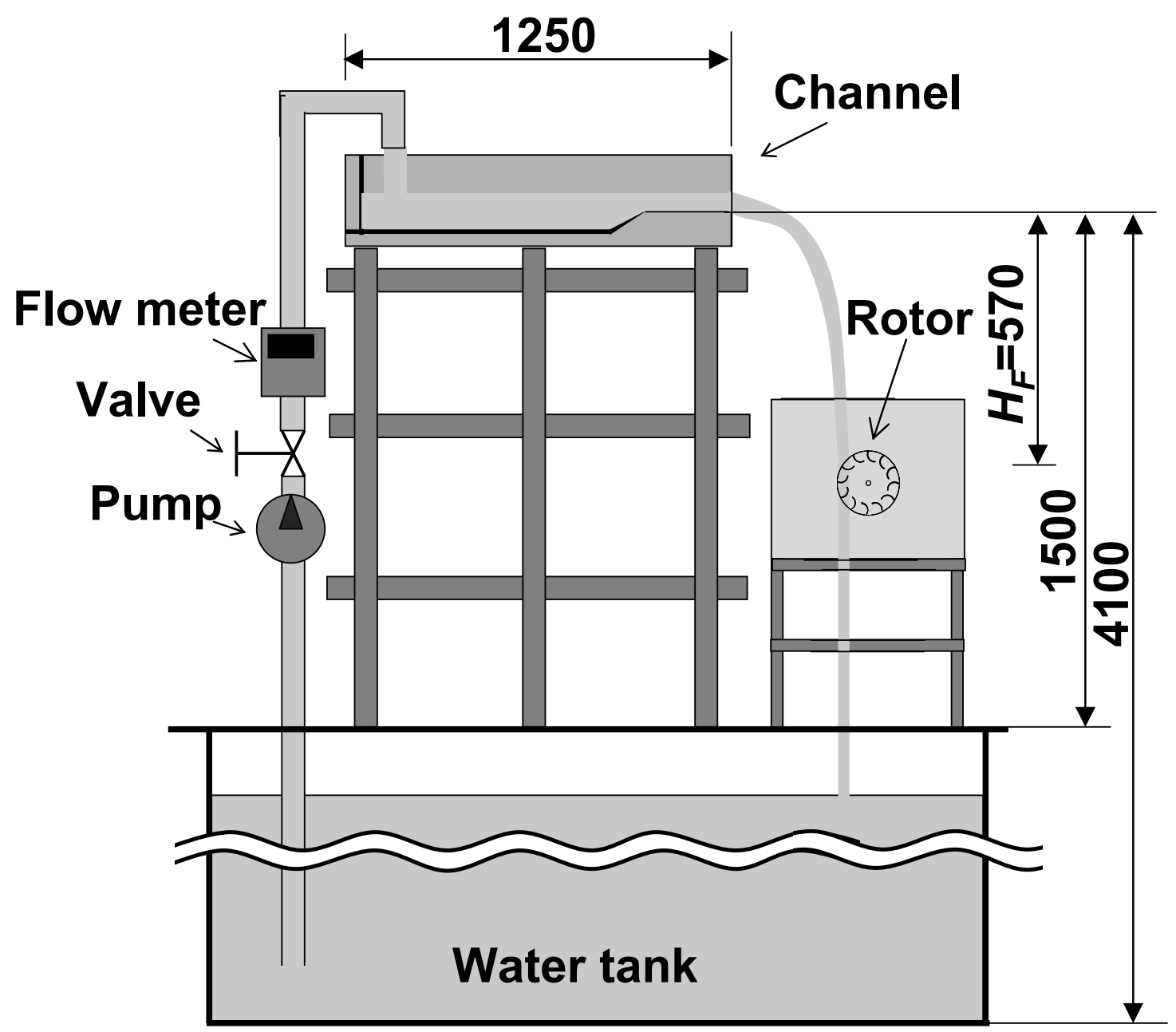

Fig. 1 

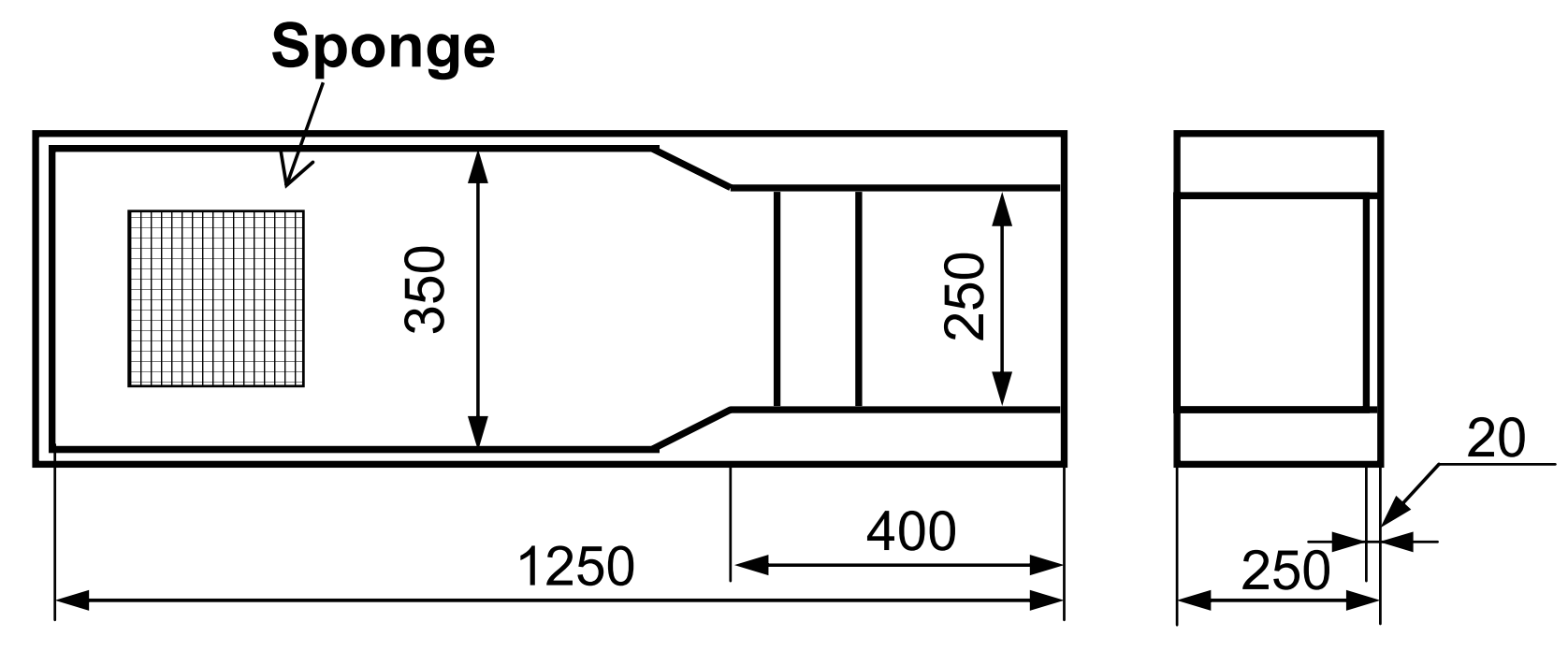

Fig. 2 


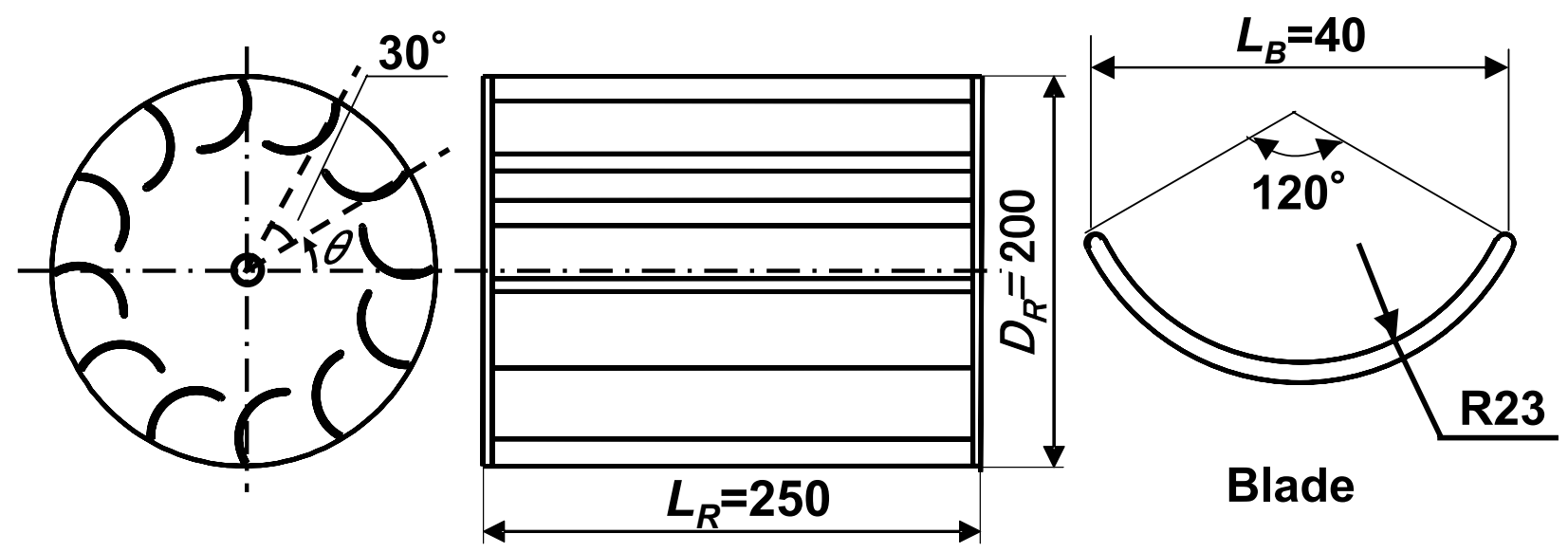

Fig.3 


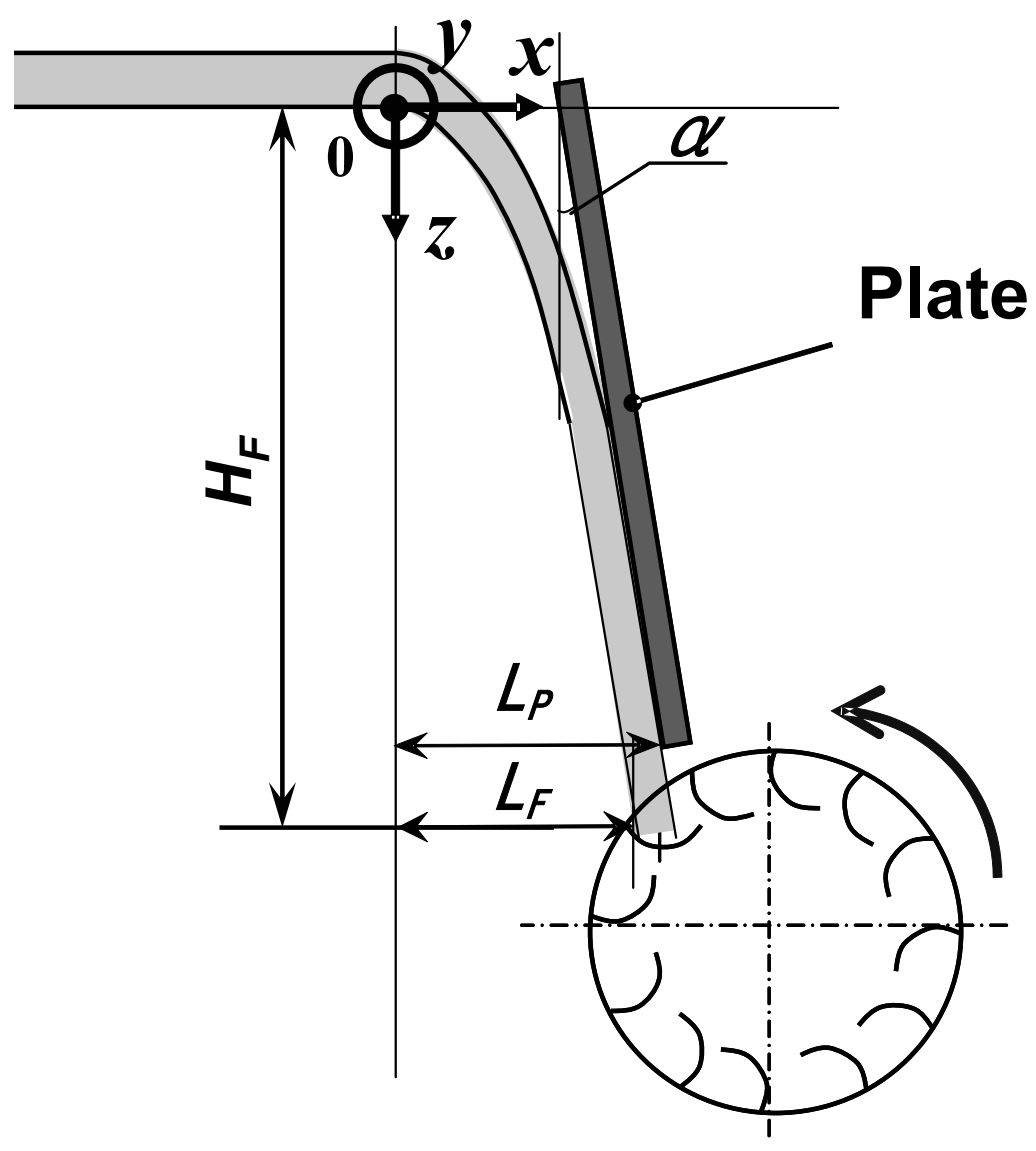

Fig.4 

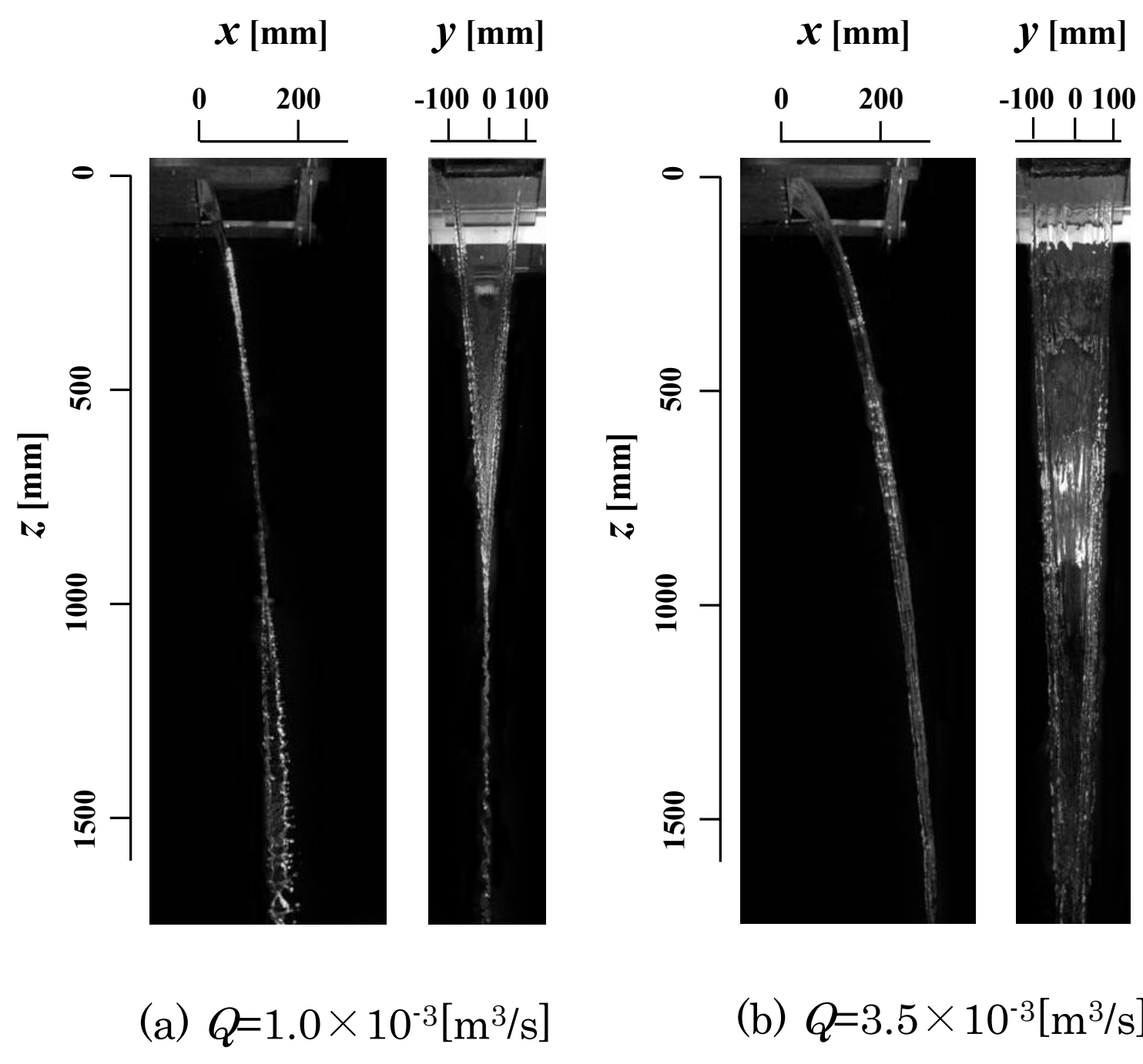

(b) $Q=3.5 \times 10^{-3}\left[\mathrm{~m}^{3} / \mathrm{s}\right]$

Fig.5 


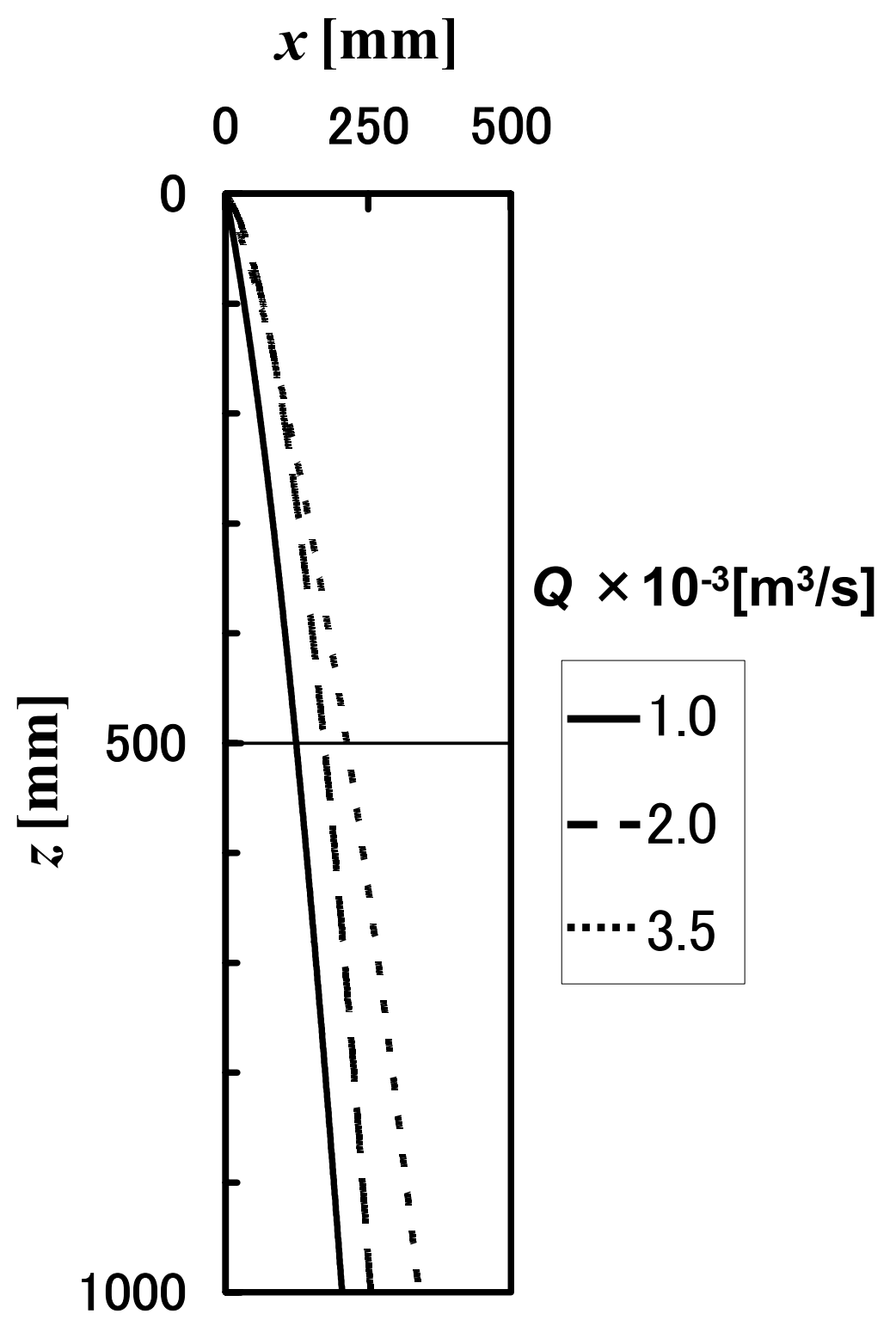

Fig.6 


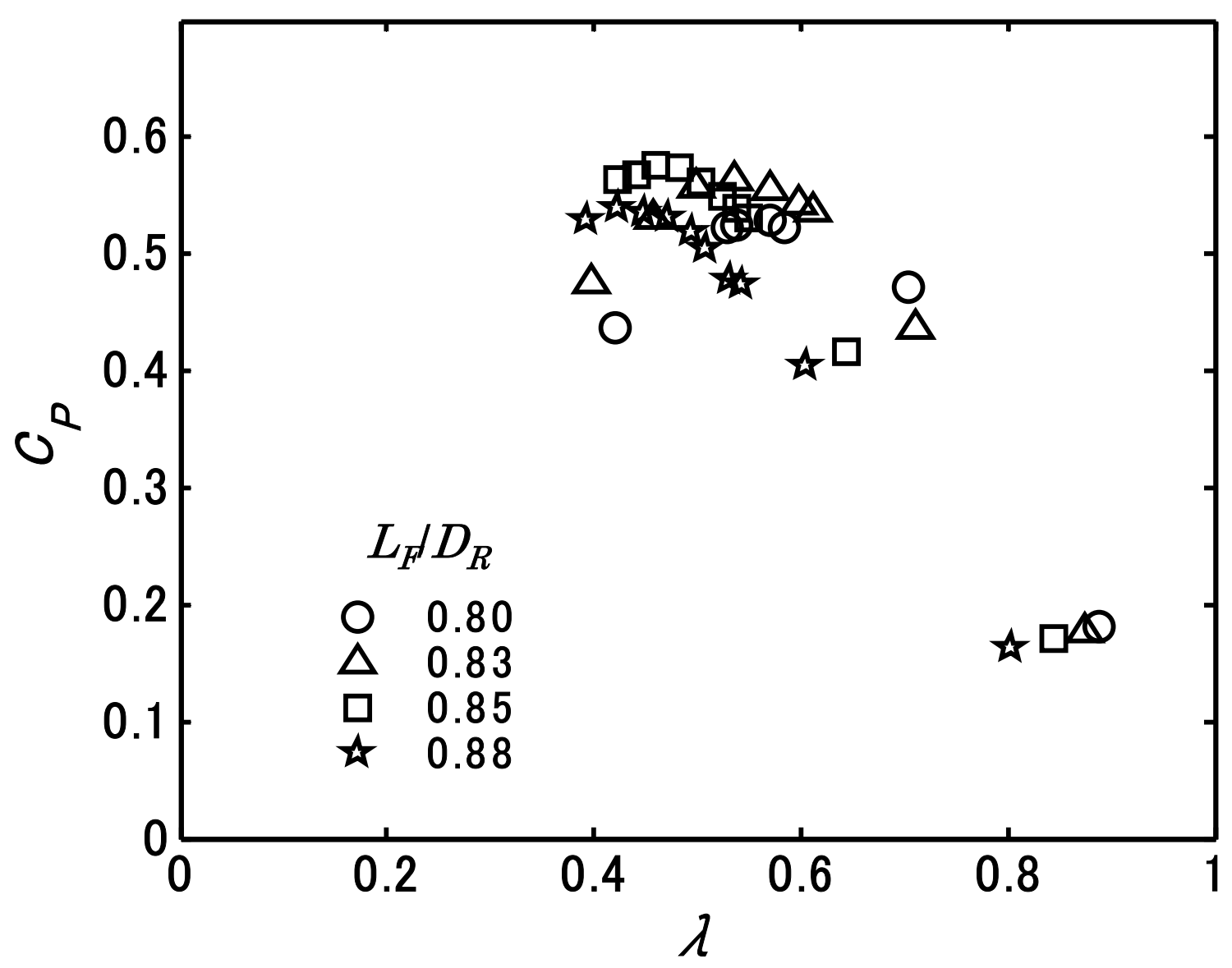

(a) $Q=1.0 \times 10^{-3}\left[\mathrm{~m}^{3} / \mathrm{s}\right]$

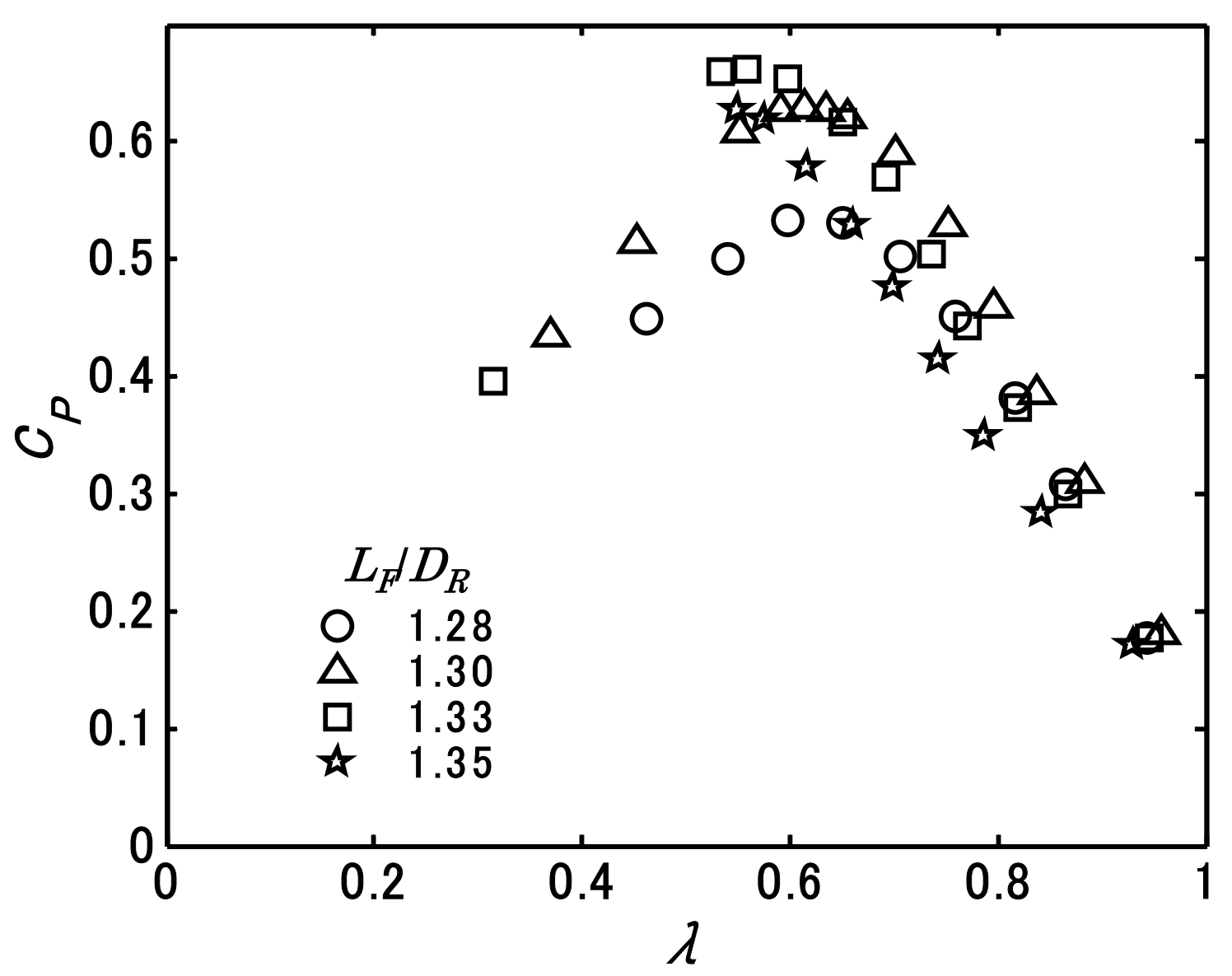

(b) $Q=3.5 \times 10^{-3}\left[\mathrm{~m}^{3} / \mathrm{s}\right]$

Fig.7 


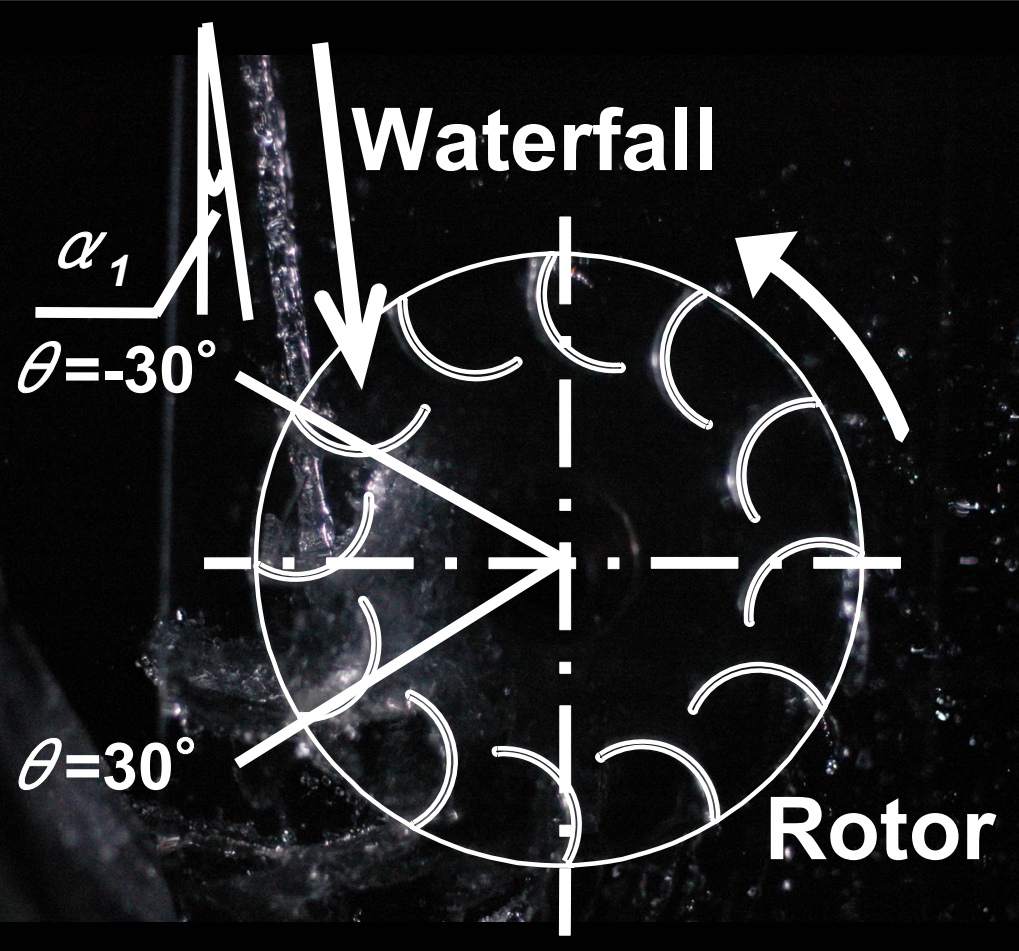

(a) $Q=1.0 \times 10^{-3}\left[\mathrm{~m}^{3} / \mathrm{s}\right], \quad \lambda=0.46, \quad C_{P \max }=0.58$

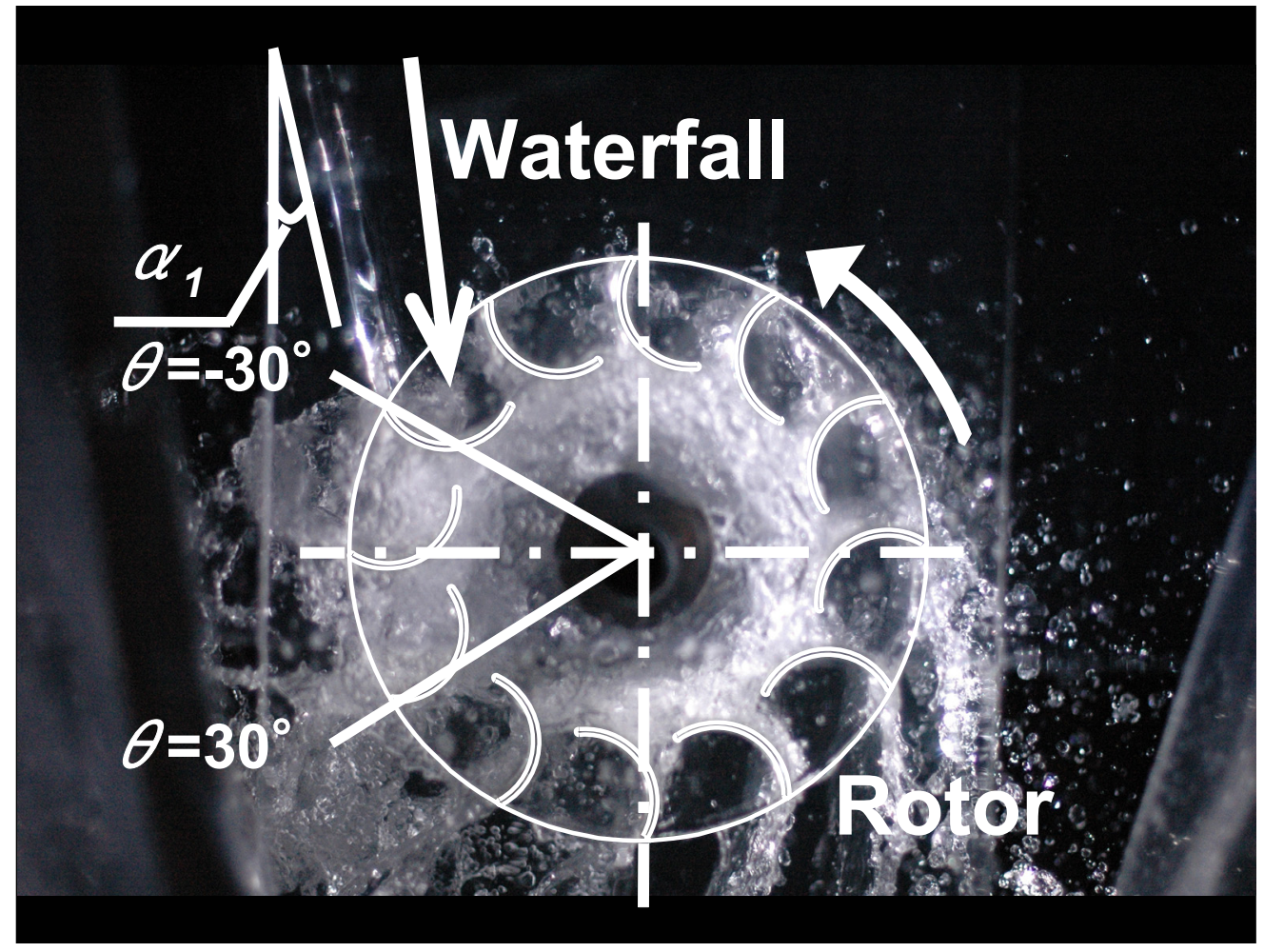

(b) $Q=3.5 \times 10^{-3}\left[\mathrm{~m}^{3} / \mathrm{s}\right], \quad \lambda=0.34, \quad C_{P}=0.40$

Fig.8 


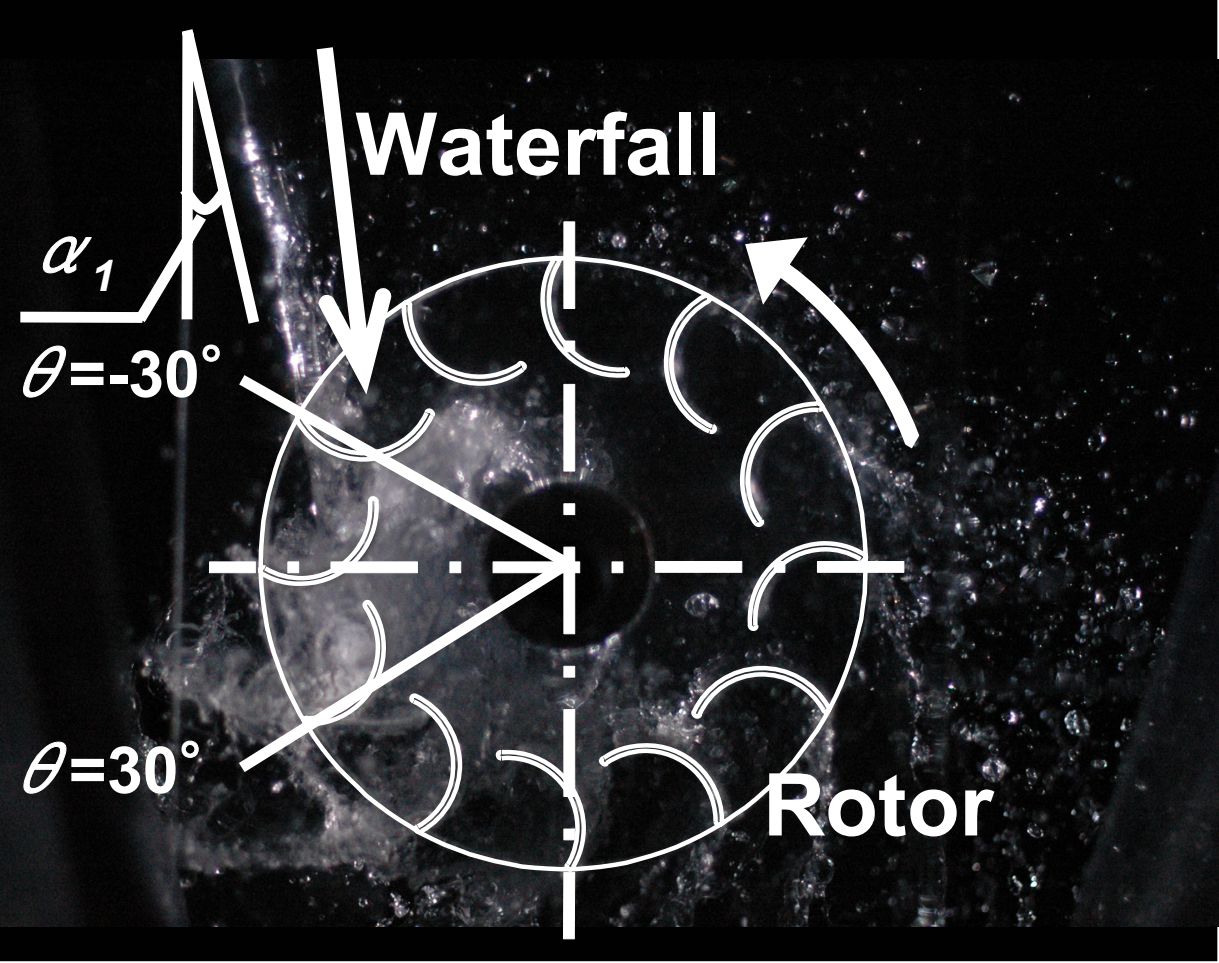

(c) $Q=3.5 \times 10^{-3}\left[\mathrm{~m}^{3} / \mathrm{s}\right], \quad \lambda=0.56, \quad C_{P \max }=0.66$

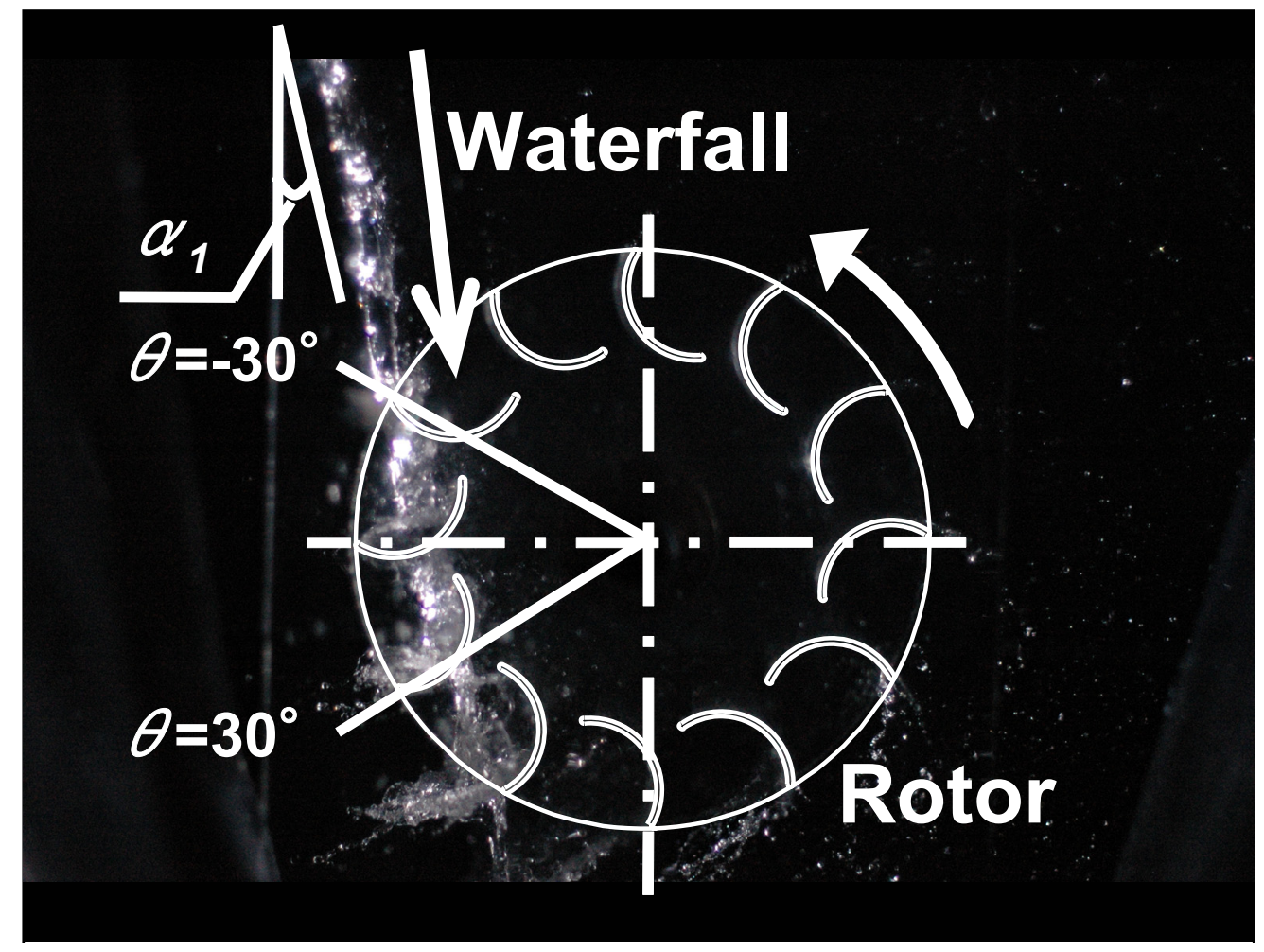

(d) $Q=3.5 \times 10^{-3}\left[\mathrm{~m}^{3} / \mathrm{s}\right], \quad \lambda=1.00, \quad C_{P}=0.06$

Fig.8 


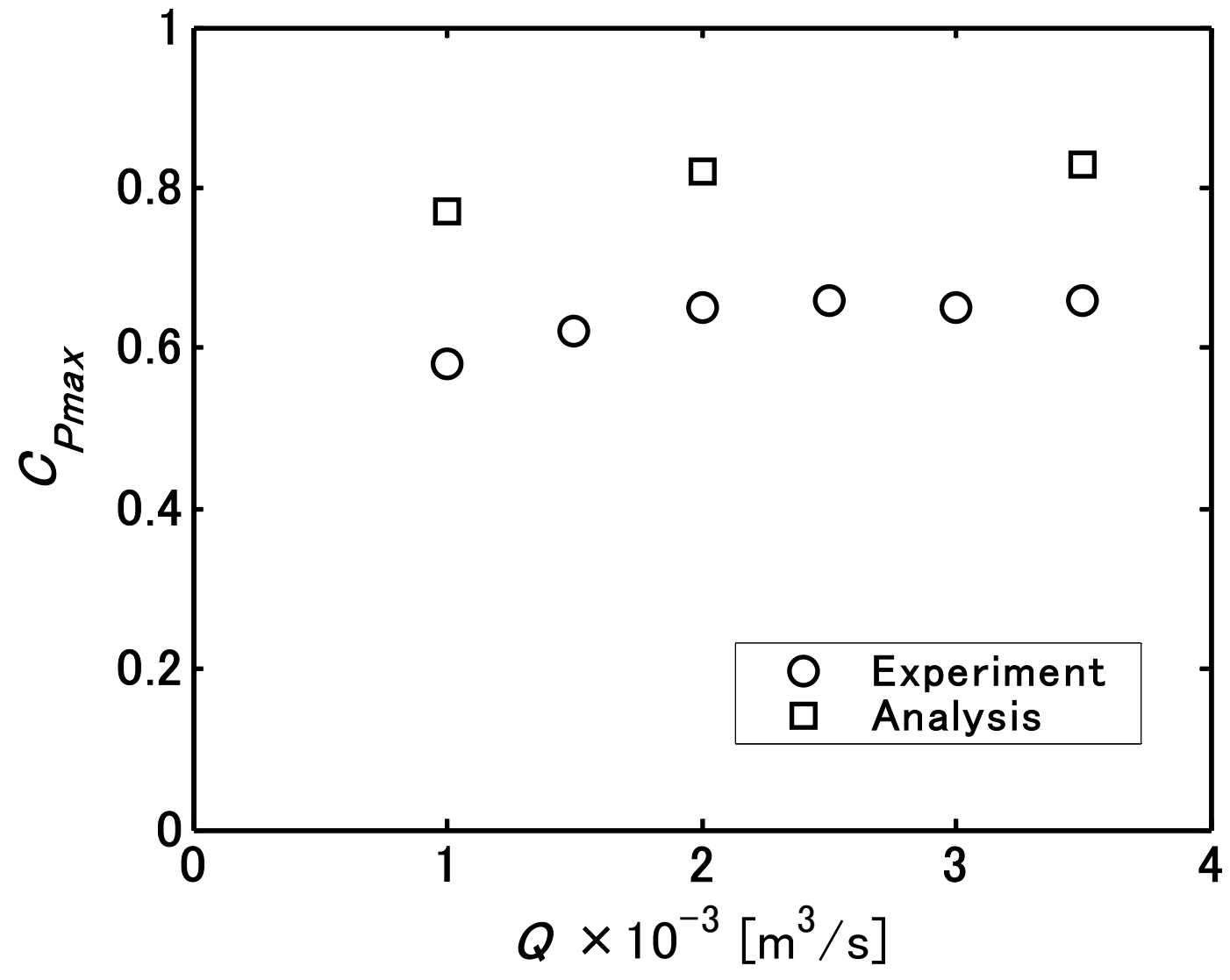

Fig.9 


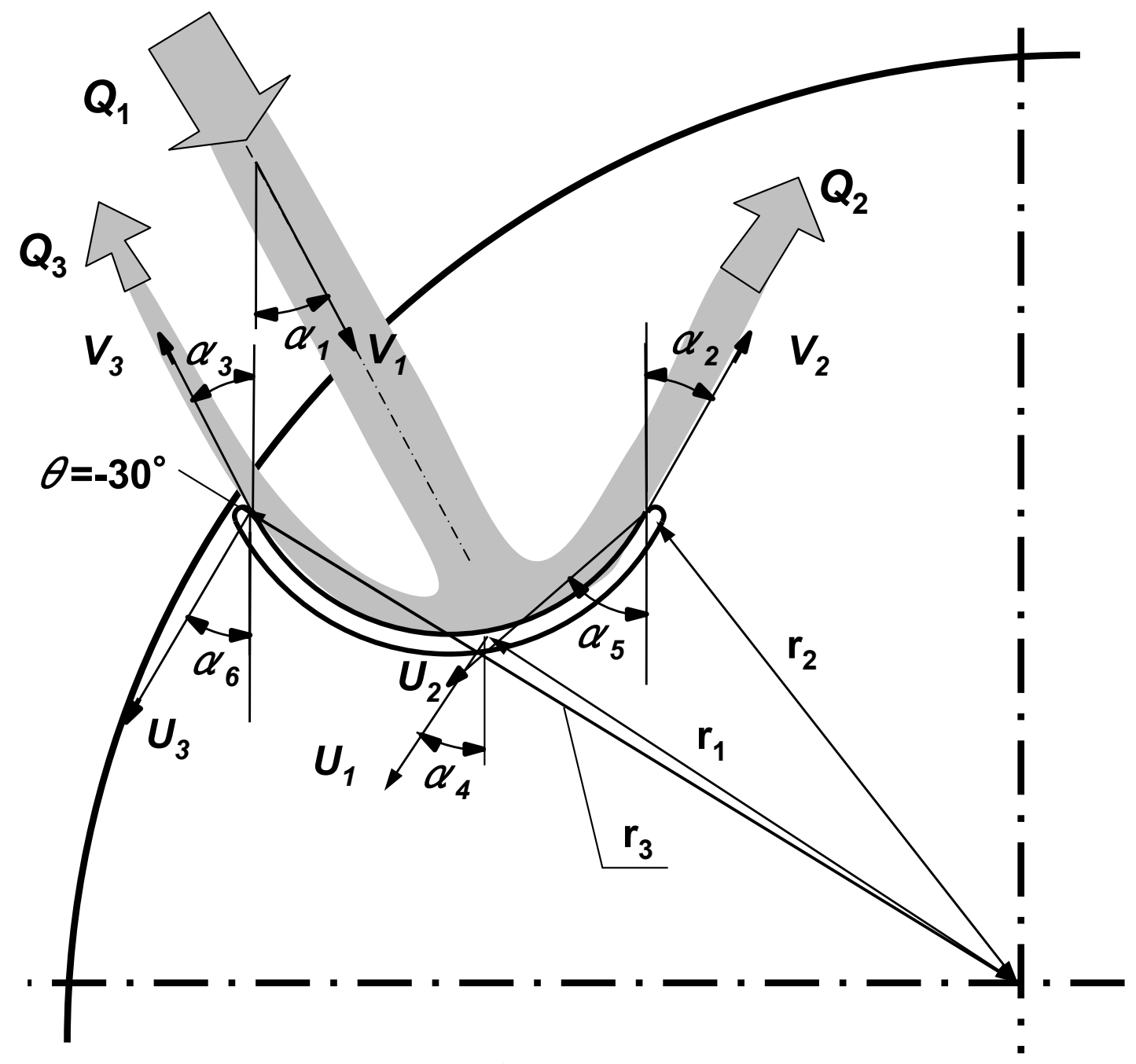

Fig.10 


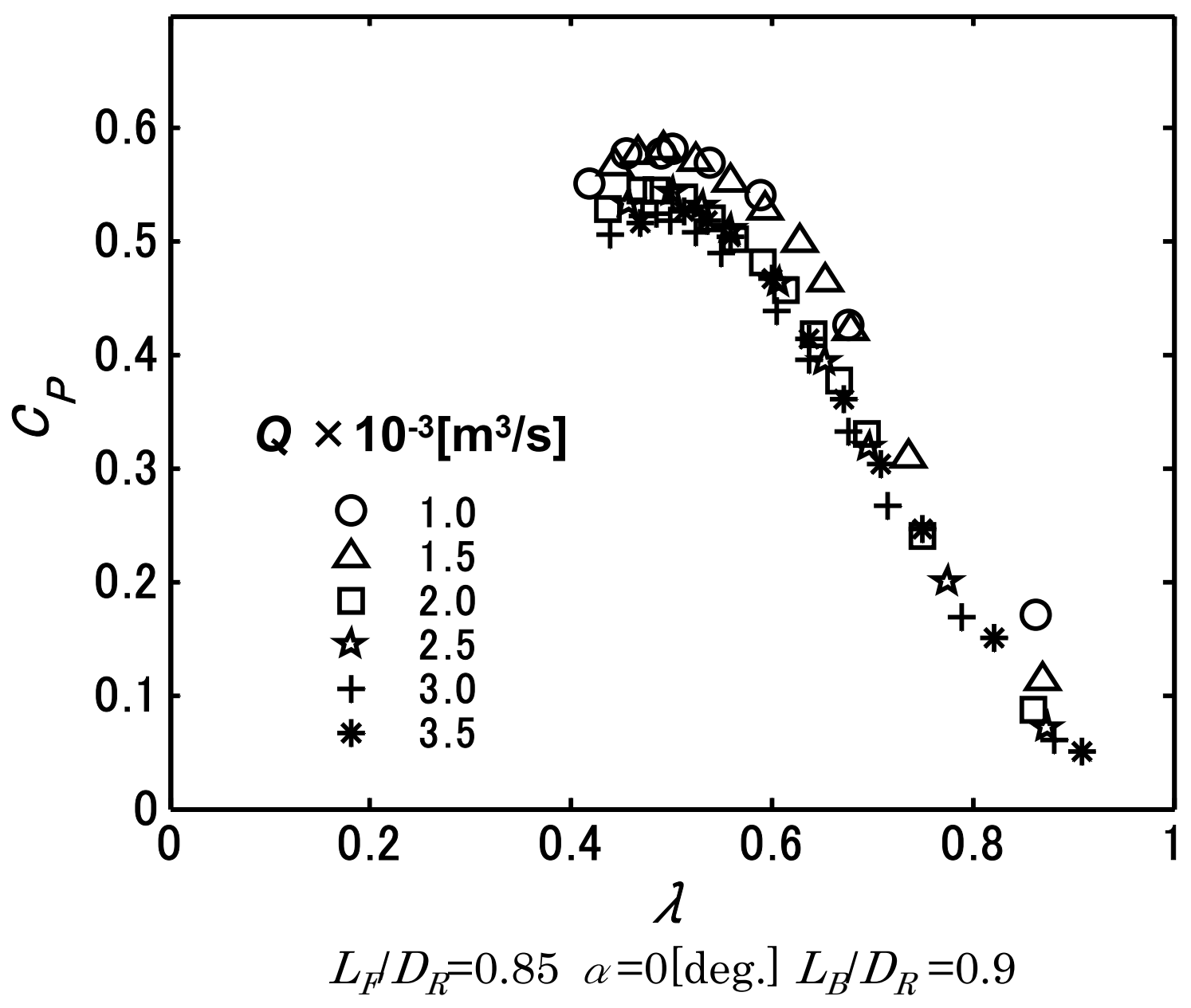

Fig.11 


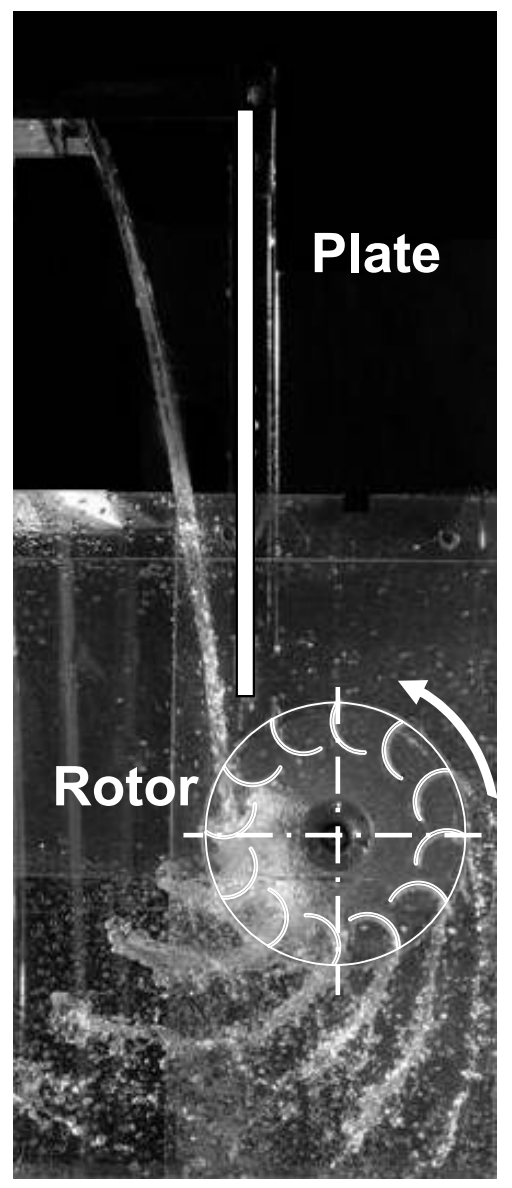

(a) $Q=1.0 \times 10^{-3}\left[\mathrm{~m}^{3} / \mathrm{s}\right]$

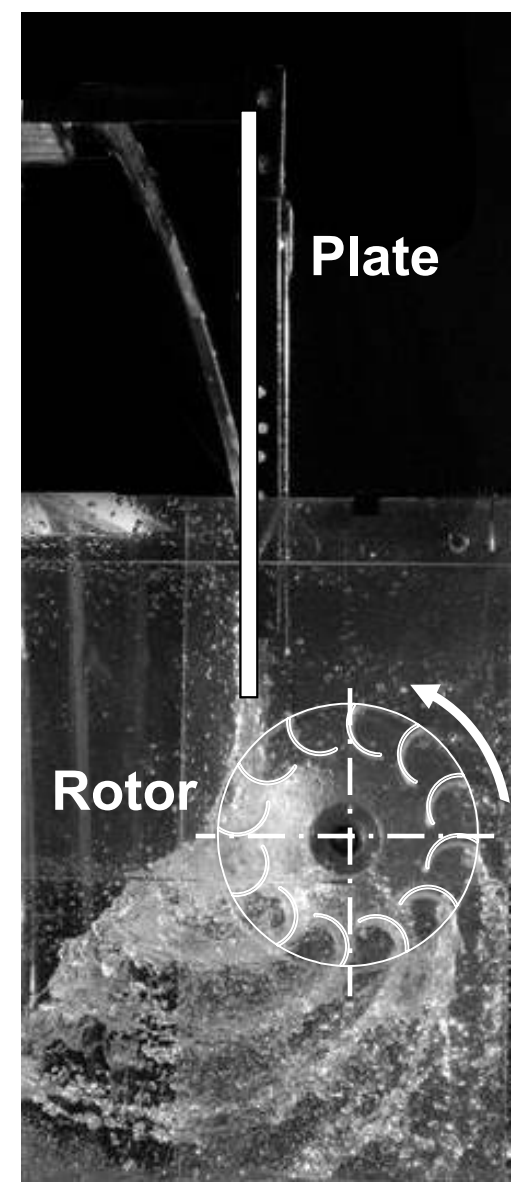

(b) $Q=2.0 \times 10^{-3}\left[\mathrm{~m}^{3} / \mathrm{s}\right]$

Fig.12

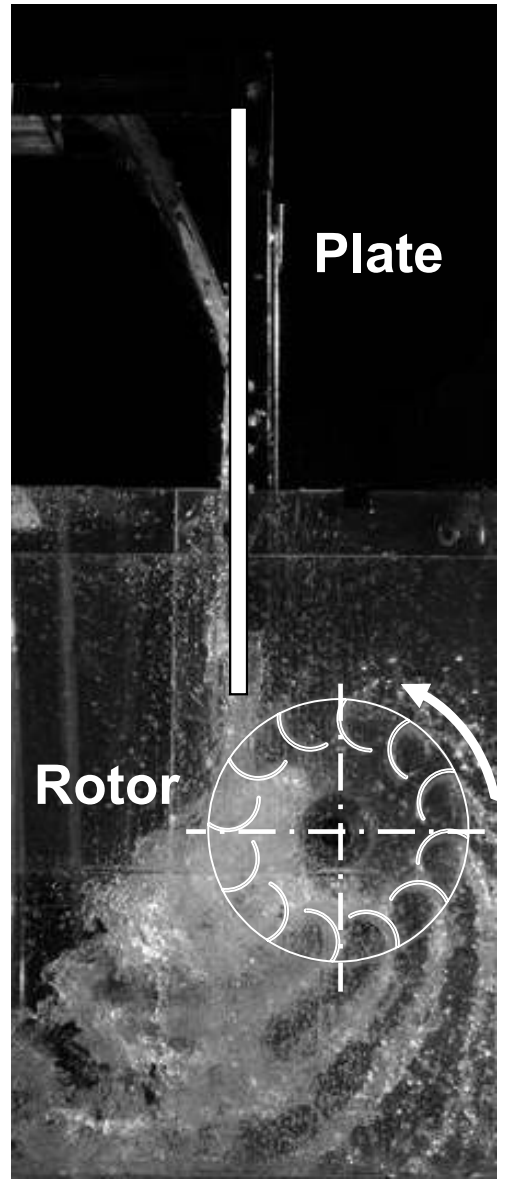

(c) $Q=3.5 \times 10^{-3}\left[\mathrm{~m}^{3} / \mathrm{s}\right]$ 


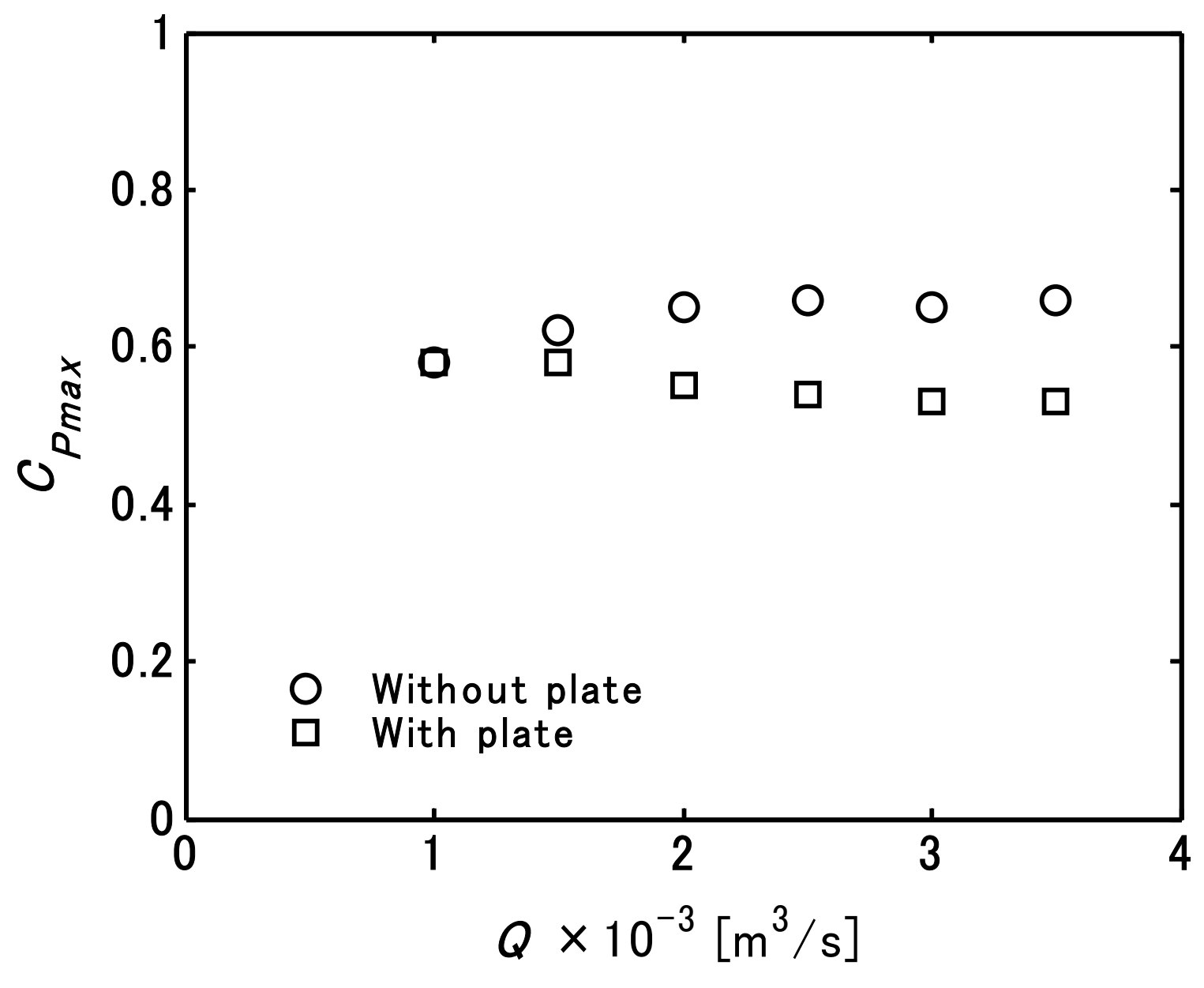

Fig. 13 

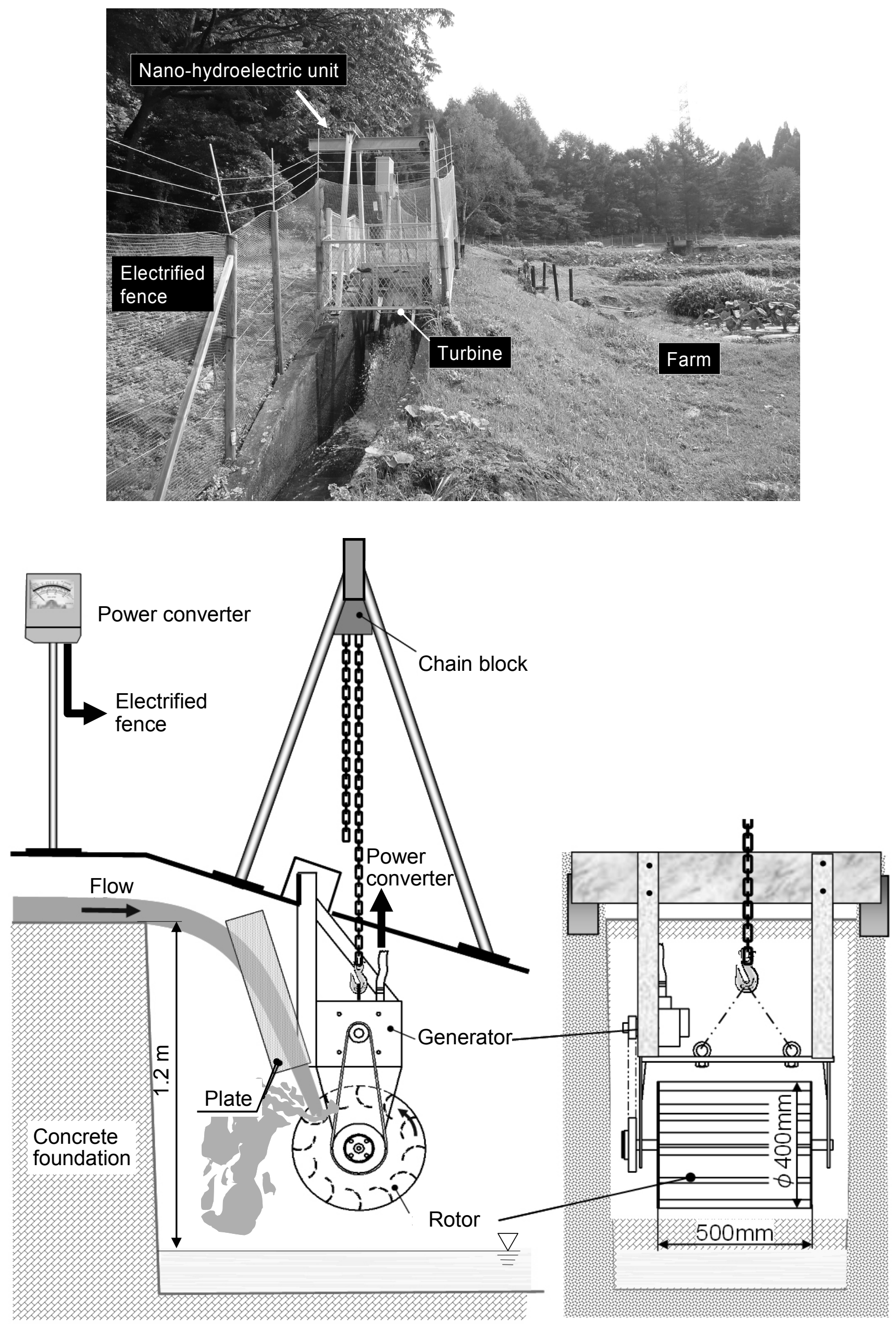

Fig. 14 
Table1

\begin{tabular}{cc}
\hline$Q \times 10^{-3}\left[\mathrm{~m}^{3} / \mathrm{s}\right]$ & $L_{F} / D_{R}$ \\
\hline 1.0 & $0.80 \sim 0.88$ \\
1.5 & $0.93 \sim 1.00$ \\
2.0 & $1.05 \sim 1.13$ \\
2.5 & $1.13 \sim 1.20$ \\
3.0 & $1.23 \sim 1.30$ \\
3.5 & $1.28 \sim 1.35$ \\
\hline
\end{tabular}

